\title{
PARA UNA RELECTURA DE LA CRÍTICA A LA RAZÓN DE THEODOR W. ADORNO Y MAX HORKHEIMER.
}

\author{
Francisco Abril \\ ...no existe ninguna afirmación, ninguna \\ “cadencia cerrada". Las contradicciones se \\ aclaran, no se resuelven. \\ Susan Buck Morss
}

La libertad consiste no en elegir entre blanco y negro, sino en escapar de toda alternativa

preestablecida.

Theodor W. Adorno

La temática que abordaré en el presente escrito es la crítica a la razón llevada a cabo por Max Horkheimer y Theodor W. Adorno durante la década de 1940, período en el cual los autores residían en California. Esta crítica se desarrolla en tres obras fundamentales. La primera es Dialéctica de la Ilustración, publicada en 1947. A ésta le siguen otras dos que, aun cuando fueron producidas individualmente, conservan el mismo propósito y hasta cierto punto el influjo de ambos temperamentos intelectuales. Se trata de la Critica de la Razón Instrumental de Horkheimer y de los aforismos de Adorno Minima Moralia, compuestos entre 1944 y 1947.

Las preguntas que buscaré responder son las siguientes: ¿Constituye el pensamiento conjunto de Adorno y Horkheimer una crítica radical a la razón? Si así fuera, ¿no implicaría una serie de problemas meta-teóricos, el más importante de los cuales sería criticar a la razón que sirve como condición de posibilidad de la crítica?

Para responder a estas interrogantes dividiré mi trabajo en dos partes. En la primera voy a abordar los motivos recurrentes de la crítica a la razón. En la segunda, elaboraré una sucinta reconstrucción de dos interpretaciones

* Licenciado en Comunicación Social y en Filosofía por la Universidad Nacional de Córdoba. E-mail: franciscoabril_2@hotmail.com 
contrapuestas de las obras mencionadas: por un lado, la de los miembros de la segunda generación de la Escuela de Frankfurt, en particular la de Jürgen Habermas y la de Albrecht Wellmer. Por otro lado, la de Juan José Sánchez (comentarista español, autor del estudio introductorio a la Dialéctica de la Ilustración publicada por Trotta en el año 2001). Mi propuesta va a consistir en advertirle a este último autor que, en su justificado afán de distanciarse de la lectura habermasiana y de la postmoderna, termina debilitando el tono contradictorio y negativo de la filosofía conjunta de Adorno y Horkheimer.

\section{Primera parte: motivos recurrentes de la crítica a la razón.}

\section{El momento regresivo de la Ilustración}

Para Adorno y Horkheimer, el término Ilustración no puede reducirse a su clásica referencia al Siglo de las Luces. Hay que remontarse al momento en que el pensamiento racional comienza a diferenciarse del mito y llegar hasta a la época de la Industria Cultural. Existe, a su vez, un sesgo negativo y crítico en la definición que proporcionan los autores. Sesgo que refiere tanto a la génesis patológica de la racionalidad occidental ${ }^{1}$, como al "carácter dual"2 que sirve como nota distintiva del desarrollo de la Ilustración y termina conduciéndola a una nueva forma de idolatría relacionada al principio de dominio.

Hay dos características propias del modo de entender la Auflelärung del siglo XVIII que se preservan en la definición de Adorno y Horkheimer: la primera de ellas consiste en la creencia en el potencial del conocimiento científico orientado al control y explotación de los seres naturales ${ }^{3}$. La segunda refiere al ejercicio de la Ilustración en tanto que agente crítico que busca liberar al hombre del miedo mítico a la naturaleza a partir de su desencantamiento 4 . Lo cierto es que el desarrollo dual del proceso ilustrado hace que la obsesión por el control de la naturaleza se vuelva contra el

1 Dubiel, Helmut, Theory and politics. Studies in the Development of Critical Theory, Cambridge (Mass.), The MIT press, 1985, p. 91

2 Adorno, Theodor y Horkheimer, Max, Dialéctica de la Ilustración, introducción y traducción de Juan José Sánchez, Madrid, Editorial Trotta, 2001, p. 98

3 Ibidem, p. 60.

${ }^{4}$ Ibidem, p. 60. 
mismo sujeto que pretende controlarla y, a su vez, lejos de disipar el miedo mítico termina reproduciéndolo ante la sola idea de que algo escape a su afán de dominio.

La relación que la filosofía iluminista (en particular la de F. Bacon) quiere establecer entre el intelecto humano y la naturaleza es, para Adorno y Horkheimer, de tipo patriarcal ${ }^{5}$. En este sentido, la realización del saber ilustrado reside en convertirnos en amos de la naturaleza desencantada. Así, el intelecto se emplea como mero instrumento de poder y coacción; el entorno natural, por su parte, es reducido a material inerte susceptible de manipulación. Este trato instrumental permite entrever que hay un punto en común entre el mito y la Ilustración. El mito ponía a los dioses como señores de la naturaleza y del universo. La Ilustración realiza una inversión: los hombres, en virtud de su razón, están en el lugar de los dioses. Se disuelve el mito, mas no la relación antagónica con la naturaleza. Se disuelve la idolatría, mas no el principio de dominio que es elevado a la categoría de ídolo.

Según los autores, la Ilustración reincide en el temor mítico ante la posibilidad de que algo escape a su esquema conceptual, el cual pretende explicarlo y controlarlo todo ${ }^{6}$. La actitud crítica, que era nota distintiva de la Ilustración respecto al mito, se deja de lado ante el principio de dominio. Se termina haciendo de este último "el ídolo al que todo se sacrifica"7. Esta tendencia regresiva de la Ilustración, su retorno al mito, es la que la conduce a su autodestrucción y la que consolida la primacía de una idea de razón reticente a toda autorreflexión: la instrumental.

La esencia de la Ilustración es la alternativa, cuya ineludibilidad es la del dominio. Los hombres habían tenido siempre que elegir entre su sumisión a la naturaleza y la sumisión de ésta al si mismo. Con la expansión de la economía mercantil burguesa, el oscuro horizonte del mito es iluminado por el sol de la razón calculadora, bajo cuyos gélidos rayos maduran las semillas de la nueva barbarie. Bajo la coacción del

\footnotetext{
${ }^{5}$ Ibidem, p. 60.

${ }^{6}$ Ibidem, p. 70.

${ }^{7}$ Horkheimer, Max, Critica de la razón instrumental, introducción de Juan José Sánchez y traducción de Jacobo Muñoz, Madrid, Editorial Trotta, 2002, p. 125.
} 
dominio el trabajo humano ha conducido desde siempre lejos del mito, en cuyo círculo fatal volvió a caer siempre de nuevo bajo el dominio. ${ }^{8}$

\section{La primacía de la razón instrumental}

La problemática principal de la obra conjunta de los autores -el desarrollo aporético y regresivo de la Ilustración- se interpreta, en la Crítica de la razón instrumental, como la escisión de dos conceptos de razón: el objetivo y el subjetivo. La consecuencia del predominio de cualquiera de estas dos nociones sobre la otra puede, en efecto, hacer peligrar a la razón toda'.

La idea de razón objetiva ${ }^{10}$ hacía referencia, en los orígenes del pensamiento occidental, a una noción más abarcativa de lo que ahora es; ella estaba contenida en el mundo, en la naturaleza, en la realidad. Lo que significa que el universo todo estaba dotado de un orden racional; en cuanto facultad subjetiva, la razón accedía a la verdad si develaba en primer término ese orden. La concepción objetiva tenía a su vez una función ética, política y religiosa. Si el individuo era capaz de conocer la razón de ser de cada cosa, podría orientar su conducta en virtud de dicho conocimiento y orden. La razón proporcionaba criterios objetivos para determinar la acción de los hombres. El acento estaba puesto en los fines racionales de cada empresa. En palabras de Horkheimer: "Cuando se concibió la idea de razón, ésta había de cumplir mucho más que la mera regulación de la relación entre medios y fines; se la consideraba como el instrumento destinado a comprender los fines, a determinarlos"11.

Con el advenimiento de la modernidad, la idea de razón entra en un proceso de subjetivación. Esta crisis afecta profundamente al pensamiento. De ahora en más la razón no está contenida en el mundo, no pueden ya extraerse contenidos objetivos a partir de sus análisis, no pueden

\footnotetext{
${ }^{8}$ Adorno y Horkheimer, Dialéctica de la Ilustración, p. 85.

${ }^{9}$ Horkheimer habla aquí de hipóstasis. Cfr. Critica de la razón instrumental, p. 178.

${ }^{10}$ Para la caracterización que hace Horkheimer tanto de la noción objetiva de razón como de la subjetiva, véase principalmente el capítulo primero de la Critica de la razón instrumental titulado "Medios y fines", pp. 45-87.

${ }^{11}$ Ibidem, pp. 21 y 22.
} 
determinarse racionalmente los fines del comportamiento humano. Se instala en el ámbito de lo práctico un relativismo que equipara fines con medios y hace que toda decisión normativa se tome en función de intereses extrínsecos a la razón. Horkheimer, a colación de éste diagnóstico, afirma que "la razón se autoliquidó en cuanto medio de comprensión ética, moral y religiosa"12.

$\mathrm{El}$ autor distingue dos aspectos de la razón subjetiva: el formal y el instrumental. En el primero de los casos, lo distintivo es la falta de relación del pensamiento con contenidos objetivos. Se produce un vacío del sentido en las ideas y las palabras. El aspecto formalista de la razón subjetiva afecta también al pensamiento, el cual es reducido a mecanismo automático (a procedimiento lógico-formal) y regido por el principio de economía reflexiva ${ }^{13}$. Se pierde de vista finalmente la función de agente crítico propia de la Ilustración, produciéndose así "la muerte de la razón especulativa"14.

Lo distintivo del aspecto instrumental de la razón es su capitulación ante contenidos heterónomos ${ }^{15}$. La razón perdió por completo su autonomía. Regida exclusivamente por el criterio de la utilidad, se ve reducida a un medio más entre los medios (órgano de dominio) empleados por el hombre para su autoconservación. A su vez, en tanto que instrumento, forma parte del proceso social, queda sujeta a él y es incapaz de ejercerle resistencia. Ante la formalización e instrumentalización de la razón se impone un único criterio rector: el domino sobre los hombres y sobre la naturaleza.

Llegado a este punto, quisiera aclarar en qué sentido Horkheimer y Adorno afirman que tanto la Ilustración como la razón se exponen a su tendencia autodestructiva. Esta aclaración permite entrever por qué la Dialéctica proyecta, como sostiene Albrecht Wellmer, "una imagen aciaga e

\footnotetext{
${ }^{12}$ Ibidem, p. 29.

${ }^{13}$ Ibidem, p. 58.

${ }^{14}$ Ibidem, p. 57.

${ }^{15}$ Ibidem, p. 58.
} 
incluso apocalíptica"16 respecto al porvenir del proyecto ilustrado y hace que el texto en cuestión se aproxime a una crítica radical.

La Ilustración atenta contra sí misma desde el momento en que reduce toda idea de razón a su versión instrumental, desde que se totaliza una concepción que identifica sin más razón y dominio. Tal afirmación puede explicarse de dos formas complementarias: los teóricos críticos reconocen que, desde los orígenes del hombre, la razón desempeña un rol instrumental relativo a la supervivencia en el entorno natural. Esta idea permitiría presuponer que no es la razón instrumental per se lo que amenaza desde dentro a la razón y a la Ilustración, sino su desarrollo socio-histórico. Es en el contexto del capitalismo totalitario que se produce en gran medida la hipóstasis de la idea de razón instrumental.

\section{¿Crítica radical y aporética a la razón?}

Si la razón instrumental termina totalizándose sobre la Ilustración, ¿no habría, entonces, una crítica radical respecto de esta última? En principio podría afirmarse que el pensamiento técnico, teniendo en cuenta la evidencia histórica de la idolatría al dominio, prevalece ante toda otra forma de reflexión racional: la crítica, la sustantiva. Como resultado de este proceso, la Ilustración termina identificándose con su "descomposición positivista"17, con su concepción meramente instrumental y técnica. En tanto la razón ilustrada opere únicamente como órgano de dominio, la crítica de Adorno y Horkheimer puede considerarse radical.

La magnitud que adquiere la crítica de los autores termina por aproximarlos a la filosofía de F. Nietzsche. Hay en ella un cuestionamiento integral al lenguaje conceptual, a la metafísica y, en última instancia, a la razón occidental. Intérpretes como Juan José Sánchez advierten esta semejanza; lo problemático del pensamiento de los frankfurtianos,

\footnotetext{
${ }^{16}$ Wellmer, Albrecht, "Crítica radical de la Modernidad Vs. Teoría de la democracia moderna: dos caras de la teoría crítica" traducción de P. Storandt y revisión de G. Leyva, en Gustavo Leyva (comp.), La teoria critica y las tareas actuales de la crítica, México, Universidad Autónoma Metropolitana - Iztapalapa, Anthropos Editorial, 2005, p. 32.

${ }^{17}$ Adorno y Horkheimer, Dialéctica áe la Ilustración, p. 78.
} 
sostendrá, reside en el hecho de que sea "una crítica total a la razón como mero instrumento de dominio sobre la naturaleza. La Dialéctica de la Ilustración [...] se adentra en el suelo de la crítica radical de Nietzsche a la razón occidental"'18.

De darse tal aproximación, la reflexión de Horkheimer y Adorno quedaría expuesta a los mismos problemas de la filosofía nietzscheana. Toda crítica radical, según Enrique de Santiago Guervós en su trabajo introductorio a los Escritos sobre retórica de Nietzsche ${ }^{19}$, corre el riesgo de llevar a dificultades lógicas. Esto es, a contradicciones y aporías en tanto que ese cuestionamiento presupone ya una instancia racional desde la cual poder articularse. El aguijón crítico de la teoría se vuelve sobre sí mismo y, al hacerlo, compromete sus propias condiciones de posibilidad. Esta es, a fin de cuentas, la aporía en la que se encuentran Adorno y Horkheimer.

Es preciso señalar que hay, sin embargo, ciertos componentes de la Ilustración que se salvan de su descomposición positivista ${ }^{20}$. El primero de ellos es la negación determinada ${ }^{21}$. Esta no es sinónimo de ciega oposición o de asumir una actitud contra algo desde una doctrina diferente que sirva de fundamento -no otra cosa exige el principio de no contradicción. No se propone una doctrina diferente ni se la defiende porque ello iría en contra de la "prohibición de nombrar al absoluto"22 que está en el núcleo del principio de negación tal y como lo entienden los autores.

Aun cuando la filosofía de Adorno y Horkheimer tiene como piedra angular la negación, no por ello debe confundírsela con una postura escéptica. Esta última sólo utiliza la negación de manera abstracta y formal. Pasa por encima de todo juicio y de toda idea con pretensiones absolutas y termina por abandonarlas o dejarlas de lado. La negación determinada, por

\footnotetext{
18 Sánchez, Juan José, 'Sentido y Alcance de la Dialéctica de la Ilustración", introducción a la edición citada de Dialéctica de la Ilustración, pp. 31 y 32.

${ }^{19}$ Nietzsche, Fiedrich, Escritos sobre retórica, introducción y traducción de Luis E. De Santiago Guervós, Madrid, Editorial Trotta, 2000, pp. 61-69.

${ }^{20}$ Adorno y Horkheimer, Dialéctica de la Ilustración, p. 78.

${ }^{21}$ Ibidem, pp. 77-78.

22 Ibidem, p. 77.
} 
el contrario, se limita a dejar al descubierto su falsedad, sin abandonar necesariamente lo que se cuestiona.

El segundo aspecto a conservarse es el que advierte que el pensamiento ilustrado es capaz de operaciones no estrictamente instrumentales. Tiene otra función de suma relevancia, a saber: determinar su propia problematicidad y volverse introspectivamente sobre sí mismo. En este sentido el pensamiento pudo siempre a lo largo de la historia "sobrepasar" 23, a través de la crítica, el mero afán coactivo. Como sostienen los autores:

en el dominio se afirma el momento de la racionalidad como distinto de él. El carácter objetivo del instrumento, que lo hace universalmente disponible, su "objetividad" para todos, implica ya la crítica al dominio a cuyo servicio creció el pensamiento ${ }^{24}$.

$\mathrm{Si}$, como parecen sugerir Adorno y Horkheimer, existieran elementos de la Ilustración que deben conservarse y desarrollarse, ¿qué sentido tiene, entonces, hablar de crítica radical y aporética de la razón? ¿No son indicios claros de que no habría tal cosa? Considero que una respuesta afirmativa a estas cuestiones puede ser apresurada y un tanto esquemática, razón por la cual estimo necesario abordar las respuestas que distintos comentaristas han dado a esta cuestión. El principal equívoco en el que incurriría, según mi opinión, es el de pasar por alto que los mismos autores denuncian una aporía en el interior de su pensamiento conjunto ${ }^{25}$, y he explicado que ella se desprende de una crítica radical a la razón.

${ }^{23}$ M. Horkheimer, Critica de la razón instrumental, p. 178.

${ }^{24}$ Th. Adorno y M. Horkheimer, Dialéctica de la Ilustración. p. 90.

25 Ibidem, p. 53. 


\section{Segunda Parte: Lecturas divergentes respecto a la crítica a la razón.}

\section{La lectura habermasiana, o sobre la contradicción preformativa}

Según Jürgen Habermas, el principio de cosificación teorizado por Lukács en Historia y conciencia de clase se ve radicalizado en Adorno y Horkheimer hasta formar parte de una idea más amplia de razón instrumental cuya aprehensión de los entes sería fundamentalmente reificante $^{26}$. A su vez, esta idea de razón depende de una lógica aún más general de dominio de la naturaleza externa e interna. La crítica de Adorno y Horkheimer se torna tan radical, según la óptica habermasiana, que ya no queda salida a la primacía absoluta de la razón instrumental27, así como tampoco a la tendencia hacia un mundo completamente administrado.

Es tal la magnitud de la crítica a la razón que llega a rebasar sus propias condiciones de posibilidad. Es decir, aquel teórico que se comprometa con una reflexión de esas dimensiones abrazará la paradójica actividad de horadar los fundamentos de su pensamiento. La Dialéctica de la Ilustración es el resultado ejemplar de esta clase de actividad "asaz paradójica" 28 que Habermas denomina "contradicción performativa" o "realizativa". Martin Jay proporciona una definición muy clara al respecto:

La contradicción realizativa no surge cuando se afirman simultáneamente como verdaderas dos proposiciones antitéticas (A y no A), sino cuando cualquier cosa que se declare está reñida con los supuestos $\mathrm{O}$ implicaciones del acto de declararla ${ }^{29}$

${ }^{26}$ Habermas, Jürgen, Teoría de la acción comunicativa, versión castellana de Manuel Jiménez Redondo, Madrid, Taurus, 1989, tomo I, p. 483.

27 En palabras de Habermas: "Incluso la crítica a la razón instrumental sigue estando prisionera del modelo a que obedece la razón instrumental misma" (Ibidem, p. 496).

${ }^{28}$ Habermas, Jürgen, Textos y contextos, traducción e introducción de Manuel Jiménez Redondo, Barcelona, Ariel, 1996, p. 149.

${ }^{29}$ Jay, Martin, Campos de fuerza. Entre la historia intelectual y la crítica cultural, traducción de Alcira Bixio, Buenos Aires, Paidos, 2003, p. 63. 
Dicho en otros términos, la crítica escéptica a la razón (lo que declaran Adorno y Horkheimer en las tres obras aquí estudiadas) está reñida con los supuestos ilustrados, racionales y discursivos del acto mismo de declararla. Es preciso destacar -y volveré sobre esta cuestión en las conclusiones- que los primeros miembros de la denominada Escuela de Frankfurt no buscaron eludir ni ocultar la aporía, sino persistir en ella. Esta actitud representa, para Habermas, una debilidad epistemológica. A ella hay que sumarle, además, que la filosofía de la vieja teoría crítica debe considerarse una tentativa "retardadora" 30 e inactual teniendo en cuenta el nuevo paradigma de la intersubjetividad en el que, según el mismo Habermas, se ha instalado la filosofía contemporánea.

Esta última afirmación es, a mi entender, muy problemática. ¿Retardadora con respecto a qué? ¿A su propio recorrido del desarrollo de la filosofía contemporánea ${ }^{31}$, la cual llamativamente conduce a su propia Teoría de la Acción Comunicativa o al paradigma (de la intersubjetividad) que sirve de plataforma para que dicha teoría pueda llevarse a cabo? Hablar en estos términos, ¿no constituye una renovación, en el plano teórico, del esquema teleológico característico de la historiografía triunfalista que tanto cuestionaron Benjamin, Adorno y Horkheimer?32 Habermas, entonces, pareciera estar abordando las principales tesis de la Dialéctica desde y en función de su propio marco conceptual (para usar una expresión de

${ }^{30}$ Habermas, Jürgen, El discurso filosófico de la modernidad, versión castellana de Manuel Jiménez Redondo, Madrid, Taurus ediciones, 1989, P. 134.

${ }^{31}$ Esto mismo se ve con particular claridad en su ya citado libro El discurso filosófico de la Modernidad.

32 Esta idea la sugiere Zamora en uno de sus artículos (aunque específicamente se refiera a la teoría de la evolución social): "la teoría de Habermas entresaca de la historia sólo aquellos acontecimientos que confirman la dilución comunicativa de instituciones prelingüísticas y soslaya las quiebras históricas, regresiones y discontinuidades, presentándose como una historiografía triunfalista que reprime la historia real de sufrimiento de las víctimas $\sin$ nombre. La teoría de la evolución social de Habermas podría ser vista como una 'ratio-dicea' formal" (Zamora, José A., "Trascendencia desde dentro - idea de reconciliación: Habermas y Adorno frente a la teología", Taula, 23-24, 1995, p. 42. Cursiva mía). 
Wellmer), no desde la singularidad del planteo crítico presentado en dichos fragmentos ${ }^{33}$.

\section{Problemas de gramática profunda: el análisis de A. Wellmer}

Los términos con los que Albrecht Wellmer suele caracterizar la crítica a la razón contenida en la obra conjunta de Adorno y Horkheimer son llamativos por su particular intensidad. La denomina, por ejemplo, "crítica radical a la modernidad" 34 , "modernidad radicalmente ensombrecida" 35 , o "postura desesperada de una Teoría Crítica" 36 . En estos términos está cifrada, por así decirlo, la radicalidad que Wellmer adjudica al cuestionamiento de la Ilustración, la razón y la modernidad que llevan a cabo los miembros de la primera generación de la escuela de Francfort.

Wellmer subraya que la crítica a la razón, debido a su magnitud, está signada por "problemas de gramática-profunda" 37 (dificultades de segundo orden relativas a las decisiones estructurales de su teoría). El más notorio lo representa la denuncia respecto de que la crítica de los fundadores de la escuela de Frankfurt sería absolutista ${ }^{38}$. Según el autor de Finales de Partida, el diagnóstico que se desprende de la Dialéctica se funda en una teoría

33 Juan José Sánchez afirma algo similar: “...ambas lecturas [la dominante -la de Habermas y la de Wellmer- y la posmoderna / postilustrada -Lyotard y Rorty, entre otros-] sacan de estos textos solamente la significación que viene a confirmar sus propias posturas, pasando por alto, o no percibiendo siquiera, el contenido crítico de los mismos, que no se deja reducir ni a uno ni a otro extremo" (Sánchez, Juan José, "Desde la memoria de las víctimas: Contribución de Horkheimer y Adorno al debate actual de la racionalidad", Memoria Académica de los seminarios impartidos por el autor en el Instituto Fe y Secularidad en 1998-1999, Madrid, pp. 44 y 45).

${ }^{34}$ Wellmer, Albrecht, "Crítica radical de la Modernidad Vs. Teoría de la democracia moderna: dos caras de la teoría crítica".

${ }^{35}$ Ibidem, p. 33.

${ }^{36}$ Wellmer, Albrecht: "Razón, Utopía y la Dialéctica de la Ilustración”, en Richard J. Bernstein (comp.), Habermas y la Modernidad, traducción de Francisco Rodríguez Martín, Madrid, Cátedra, 2001, p. 84.

${ }^{37}$ Wellmer, Albrecht, Sobre la Dialéctica de la modernidad y la posmodernidad, traducción de José Luis Arántegui, Madrid, Visor, 1993, p. 65.

38 Ibidem, p. 103. 
reduccionista de la razón que identifica o traduce todo pensamiento en términos de pensamiento identificante (dejando de lado posibles excepciones). Esta concepción conformaría una idea de razón cientificista e ilustrada a la medida de su propio cuestionamiento, es decir, con sus caracteres distintivos "negativísticamente predecididos"39.

Por otra parte, para Wellmer la crítica que se expresa en la Dialéctica de la Ilustración sólo puede formularse si se presupone una esfera transdicursiva de verdad (el arte contemporáneo, para Adorno) y un horizonte utópico y mesiánico (la ruptura con el continuum de la historia de la que habla W. Benjamin en sus Tesis sobre el Concepto de Historia) que validan de antemano la crítica en cuestión. Estos presupuestos configuran una "óptica dogmática"40 a partir de la cual condenar de forma absolutista la razón, la Ilustración y la modernidad. En definitiva, lo que resultaría problemático en el planteamiento de Horkheimer y Adorno es "la conexión [...] entre negativismo y mesianismo" 41 .

Pese a estos cuestionamientos, Wellmer se niega a considerar retardadora a la filosofía conjunta de los frankfurtianos. Habla de la existencia de una "oculta y paradójica unión"42 que permitiría integrar a la Dialektik der Auflelärung en el marco de "una forma democráticamente ilustrada de la Teoría Crítica"43. Lo que propondría es que la moderna teoría de la democracia (en particular, la de Habermas) se apropie del impulso radicalmente trascendente que se manifiesta en la Dialéctica a los fines de ejercer una crítica ideológica de conceptos como el de Derechos Humanos, Justicia, etc. En palabras de Wellmer:

39 Wellmer, Albrecht, Finales de Partida: la modernidad irreconciliable, traducción e introducción de Manuel Jiménez Redondo, Madrid, Ediciones Cátedra, 1996, p. 247.

40 Ibidem, p. 244.

41 Ibidem, p. 244.

42 Wellmer, A. "Crítica radical de la Modernidad Vs. Teoría de la democracia moderna: dos caras de la teoría crítica", p. 40.

43 Ibidem, p. 40. 
Las formas radicales de crítica social, como la vieja teoría crítica las tiene en común con los trabajos de Foucault, se alimentan de una reinvención aún pendiente de lo que la democracia, la libertad y los derechos humanos deberían significar en un momento histórico en el que las interpretaciones ya establecidas de estas ideas no tienen una función correctiva notable frente a las patologías, relaciones de poder e injusticias sociales ya manifiestas y, en este sentido, ya se amalgamaron con ellas ${ }^{44}$.

Hay dos puntos que considero discutibles en el planteo de este comentarista. El primero es que tiende a identificar la crítica radical con un recurso a la exageración ${ }^{45}$, con lo cual no hace más que relativizar la radicalidad y, por ende, el carácter aporético del pensamiento de Adorno y Horkheimer. El segundo es que al llamar absolutista a la vieja teoría crítica pierde de vista el rol que en ella cumple la negación determinada. No obstante, es muy sugestiva la pretensión de Wellmer de re-significar el valor de la radicalidad (para el cual puede prescindir de la idea de exageración) y el afán aporético que detenta la Dialéctica en el seno del horizonte normativo de una teoría de la democracia moderna.

\section{La interpretación en clave de perspectiva de las víctimas}

Juan José Sánchez es uno de los comentaristas españoles que se opone a la lectura canónica que hacen Habermas y Wellmer. Insiste en destacar que la Dialéctica no se propone ni la negación ni el abandono de la Ilustración; el tono crítico de esta obra refiere fundamentalmente a la primacía histórica de una concepción particular de razón instrumental ${ }^{46}$. De igual modo, no se condena sin más toda expresión de progreso en la historia, sino el alto precio que debió pagarse para alcanzarlo, sus consecuencias más negativas y devastadoras.

La crítica radical está, entonces, circunscripta al horizonte histórico (y, por lo tanto, no puede considerarse totalizadora) en el que la razón

44 Ibidem, p. 39.

45 Ibidem, p. 43.

${ }^{46}$ Sánchez, J. J., "Desde la memoria de las víctimas: Contribución de Horkheimer y Adorno al debate actual de la racionalidad", p. 48. 
tiende a identificarse cada vez en mayor medida con el dominio. Es radical, pero en un sentido restringido -lo que no deja de ser paradójico. De esta observación se desprenden, al menos, dos conclusiones convergentes entre sí: que no hay una "crítica total" 47 a la razón (es decir, de carácter estructuraly no sólo coyuntural) y que, por ende, la aporía no constituye un callejón sin salida (se puede "preservar a los autores de la contradicción"48).

Para Sánchez está claro que el propósito de los frankfurtianos consiste en elaborar un "Concepto Positivo" y "salvar" a la razón a partir de su autorreflexión. El debate es, entonces, "entre razón y razón"49; es decir, una noción crítica de razón que ejerza resistencia contra su autocomprensión instrumental. También es necesario aclarar que la Dialéctica busca dar cuenta de la visión del Ángelus Novus (el pasado se presenta ante sus ojos no como una "cadena de acontecimientos", sino como una "única catástrofe") de la que habla W. Benjamin en su famosa tesis $\mathrm{IX}^{50}$. A partir de esta mirada rememorativa, que no es ni escéptica ni mesiánica como sostienen Habermas y Wellmer respectivamente, debe analizarse el texto de Adorno y Horkheimer. Para comprender la singular radicalidad de la crítica a la Ilustración -y este es el punto nodal de la propuesta de Juan José Sánchezes preciso abordarla desde la perspectiva de las víctimas. Lo importante es recuperar:

la visión de la historia en cuanto bistoria de sufrimiento, de la historia tal como aparece a los ojos de sus víctimas, de la historia del progreso desde

${ }^{47}$ Sánchez, J. J., 'Dialéctica de la Ilustración: actualidad crítica de una nueva lectura', Memoria Académica de los seminarios de impartidos por el autor en el Instituto Fe y Secularidad en 1997-1998, Madrid, p. 33.

48 Sánchez, J. J. "Sentido y Alcance de la Dialéctica de la Ilustración", introducción a la edición citada de Dialéctica de la Ilustración, p. 29.

49 Sánchez, J. J., 'Desde la memoria de las víctimas: Contribución de Horkheimer y Adorno al debate actual de la racionalidad', p. 32.

${ }^{50}$ Löwy, Michael, Walter Benjamin. Aviso de Incendio, traducción de Horacio Pons, México, Fondo de Cultura Económica, 2003, pp. 100-101. 
la conciencia del precio que la humanidad paga por él, de los costes de la felicidad de los felices ${ }^{51}$.

Este comentarista hace dos afirmaciones muy importantes respecto al carácter contradictorio de la crítica: en primer lugar, trata de no perder de vista que la aporía no es sólo teórica, sino principalmente socio-histórica. En segundo lugar, sostiene que la aporía dista de ser un déficit epistemológico (Habermas); es, contrariamente, el "topoi" 52 o la estrategia argumentativa propiamente dicha de la Dialéctica.

En mi opinión -como argumentaré en las conclusiones-, en el trasfondo del planteo de Sánchez hay una renuencia explícita a leer la Dialéctica en términos de crítica total, pero a su vez hay reparos (al que obedece, entre otras cosas, la distinción entre crítica radical y total) en no hacerlo porque ello implica una dilución de la aporía (ante la cual el autor tiene una actitud ambivalente; por un lado, reconoce su existencia y función y, por otro lado, busca preservar a Adorno y Horkheimer de la contradicción). Esta última se suscita, justamente, si la condición de posibilidad de la crítica se ve afectada por la crítica misma, lo cual no ocurre en la medida en que se visualicen dos concepciones diferentes de razón (una de carácter crítico y otra meramente instrumental).

\section{Conclusiones}

\section{Una dimensión no erradicable de radicalidad}

El hecho de que los teóricos críticos reconozcan que existe una aporía ínsita en su pensamiento es -he aquí la respuesta al primer problema planteado en la introducción- el principal motivo por el que afirmo que hay una dimensión de radicalidad en su crítica que no puede ser eludida ni minimizada. La contradicción consiste, justamente, en que cuestionan sin miramientos a la Ilustración y al mismo tiempo se niegan a renunciar a ella, a

${ }^{51}$ Sánchez, J. J., “Quebrar la lógica del dominio", estudio introductorio a la Crítica de la razón instrumental de Horkheimer, Madrid, Editorial Trotta, 2002, p. 17.

52 Zamora, José A., "Civilización y barbarie. Sobre la Dialéctica de la Ilustración en el 50 aniversario de su publicación”, Scripta Fulgentina, Nro. 14, 1997, p. 257. 
la razón, a los ideales de la modernidad. Si ese cuestionamiento fuera parcial, si sólo se pusiera en tela de juicio una determinada concepción instrumental de Ilustración desde una racionalidad crítica subyacente, no tendría sentido hablar de contradicción ni de aporía puesto que la instancia crítica y la instancia criticada no coincidirían.

Ahora bien, radicalidad no es equivalente a un "desbocado escepticismo frente a la razón ' 53 (Habermas) o a un "carácter absolutista de la crítica de la razón"54 (Wellmer). Para desmentir estas expresiones no es necesario remitirse a los polos positivos de la filosofía de los primeros teóricos críticos como hace Juan José Sánchez; basta con señalar cuán significativos resultan en ella los recursos, mutuamente convergentes, de la negación determinada y la contradicción. No hay escepticismo porque la negación no deja de conservar, siquiera implícitamente, la verdad relativa de aquello que sin embargo cuestiona sin miramientos. Es decir, la negatividad no es sinónimo de oposición o de asumir una actitud contra algo, desde una doctrina diferente que sirva de fundamento.

No obstante, esto no significa que a partir de esta verdad relativa se reconstruya una instancia positiva de reflexión; la negatividad se basa en observar la "prohibición de nombrar al absoluto" 55 , la prohibición de remover una idolatría para proponer una nueva. Como mostraré a continuación, la idea de cuestionar algo sin por ello abandonarlo o proponer algo diferente se encuentra en el punto nodal de la estrategia argumentativa saber: la contradicción- que emplean Adorno y Horkheimer.

\section{Una crítica que busca persistir en la aporía}

Hay un aforismo de la Dialéctica ${ }^{56}$ que explica y justifica la posición aporética de sus autores, amén de dar los indicios necesarios para responder al segundo problema que busqué dilucidar en este escrito. En ese aforismo Adorno y Horkheimer se defienden contra quienes, exigiéndoles coherencia,

\footnotetext{
${ }^{53}$ Habermas, J., El discurso filosófico de la modernidad, p. 161.

54 Wellmer, A., Sobre la Dialéctica de la modernidad y la posmodernidad, p. 103.

55 Adorno y Horkheimer, Dialéctica de la Ilustración, p. 77.

56 "Contradicciones", Dialéctica de la Ilustración, pp. 283-285.
} 
los impugnan. Estos últimos no pueden entender que no haya una doctrina general que respalde su crítica al progreso, a la razón, a la ciencia y a la modernidad. No pueden entender que, aun manteniendo una actitud de profunda desconfianza, eso no implica que prefieran abandonar las instancias criticadas. Se les exige, entonces, que tomen partido por una cosa o por otra y que, obedeciendo al principio de no contradicción, lleven su reflexión hasta las últimas consecuencias. Esta es, sin duda, una forma reduccionista de comprender el cuestionamiento de los teóricos críticos que no puede librarse de la falsa "alternativa entre "esto o lo otro"'57, del engañoso esquema según el cual estás con algo (la Ilustración, la razón) o en su contra.

La mayor parte del aforismo Contradicciones está escrito en la forma de un diálogo entre dos personajes ficticios llamados A y B. En la parte central de este diálogo queda ejemplarmente prefigurada la posición de los autores, en las contribuciones del segundo personaje, respecto a su crítica y a la aporía que comporta:

B: Yo no estoy contra la razón: sólo quiero reconocer la forma que ha asumido.

A: Estás en contradicción contigo mismo.... Tu misma existencia presupone el principio al que quisieras sustraette.

B: No lo niego, pero la contradicción es necesaria. Es la respuesta a la contradicción objetiva de la sociedad ${ }^{58}$.

Este pasaje revela cuanto menos dos cuestiones: en primer lugar, que el propósito fundamental de su empresa teórica, más que el esfuerzo por elaborar un concepto positivo de razón, el cual no deja de ir en detrimento del recurso a la negación determinada que emplean los autores, es aclarar el "estado espantoso en que todo se encuentra" 59 , es reconocer la forma que, en su momento, asumió la razón. En segundo lugar, que no debe eludirse la contradicción, que la actitud aporética de los autores es una instancia necesaria para hacer un análisis de las sociedades actuales. La contradicción

\footnotetext{
${ }^{57}$ Ibidem, p. 283.

58 Ibidem, p. 284.

59 Ibidem, p. 284.
} 
representa entonces, y como bien remarca Zamora, un topoi o estrategia argumentativa en el marco de la Dialéctica de la Ilustración y no un déficit epistemológico -menos aún una teoría que, según los criterios de un nuevo paradigma que revigoriza el principio de no contradicción, debe juzgarse "retardadora" 60 - como afirma Habermas.

\section{Las contradicciones se aclaran, no se resuelven.}

Coincido con Juan José Sánchez en señalar que hay radicalidad en la crítica a la Ilustración, pero que ello no implica su abandono. Coincido, también, en entender a la aporía como topoi de la Dialéctica. Pero en un punto en particular me alejo de su planteo. Mi tesis, en este sentido, debe ser comprendida como el equivalente a una advertencia. Busca hacer ver los límites que comporta una propuesta de lectura como la de Sánchez. Lo que quiero demostrar es que su interpretación se expone al riesgo de minimizar el carácter radical y aporético de la crítica a la razón de Adorno y Horkheimer, aun cuando no deje de reconocerlo.

Mi idea no es desmentir los pasajes que respaldan la lectura de Sánchez -que existen y son bastante claros-, sino advertir que la contradicción que alberga el pensamiento de Adorno y Horkheimer se disipa cuando se hace excesivo énfasis sobre los aspectos afirmativos de su reflexión. Si la instancia critica (razón crítica subyacente) difiere de la instancia criticada (primacía de la razón instrumental), si el debate es entre razón y razón como sostiene este comentarista, entonces -y este es el punto fuerte de mi propuesta- ya no tiene sentido sostener que bay contradicción en el pensamiento de los autores. Al menos no la hay si por contradicción entendemos una crítica que compromete sus propias condiciones de posibilidad; Sánchez, por otra parte, no ofrece una definición alternativa al respecto.

A partir de esta advertencia a la que en última instancia se reduce mi proposición, se puede elaborar una nueva y en principio tentativa interpretación de la obra de los frankfurtianos que, manteniéndose equidistante de la lectura postmoderna y habermasiana, no minimice su radicalidad. Una interpretación que en lugar de poner el acento en los polos

${ }^{60}$ Habermas, J., El discurso filosófico de la modernidad, p. 134. 
positivos, los coloque en los puntos de tensión y contradicción de esa obra. De lo que se trata, entonces, es de maximizar su carácter aporético, en lugar de relativizar la crítica ${ }^{61}$. Me parece que de esta forma se hace justicia al tono crítico que la caracterizó, por sobre su tono propositivo. Se hace justicia a su voluntad de conocer el aterrador estado en que todo se encontraba y la responsabilidad que, al respecto, le competía al proyecto ilustrado en su conjunto.

\section{Resumen}

La temática que se aborda en este artículo es la crítica a la razón elaborada por Max Horkheimer y Theodor W. Adorno en tres obras fundamentales: Dialéctica de la Ilustración, Crítica de la razón instrumental y Minima Moralia. Las preguntas que se buscan responder son las siguientes: ¿Constituye el pensamiento conjunto de los autores una crítica radical? Si así fuera, ¿no implicaría una serie de problemas meta teóricos y contradicciones (como ser, cuestionar a la razón que sirve de fundamento a su pensamiento)? El escrito se divide en dos partes. En la primera se abordan los motivos recurrentes de la crítica a la razón. En la segunda, se elabora una sucinta reconstrucción de dos interpretaciones contrapuestas de las obras mencionadas: por un lado, la de los miembros de la segunda generación de la Escuela de Frankfurt, en

${ }^{61}$ En consonancia con mi propuesta, Martin Jay hace una defensa y revalorización del carácter aporético contra la crítica de Habermas en estos términos: "Su decisión [la de Adorno] probablemente pueda defenderse como un reconocimiento de que la realidad social actual (pero no algo llamado 'lenguaje') hace que resulte anormal el estado de coincidencia performativa que quiere imponer Habermas. Lo que los teóricos del acto de habla se complacen en llamar 'el feliz' u 'oportuno' resultado de los actos ilocucionarios no parece fácil de alcanzar en un mundo que no logra satisfacer otros tipos de felicidad. Y, a fortiori, la superación intersubjetiva de la contradicción tiene aún menos probabilidades de darse" (Jay, M., Campos de fuerza. Entre la bistoria intelectual y la crítica cultural, p. 77). Con esta defensa Martin Jay parece estar proponiendo una comprensión distinta a la que él mismo hizo en $L a$ Imaginación Dialéctica. En el capitulo dedicado a la crítica de la Ilustración prácticamente no hace mención a la contradicción que subyace en el pensamiento de los frankfurtianos. De hecho, es proclive a disiparla sosteniendo que Horkheimer defendía una noción de razón (Vernunft) no reducida a mero entendimiento (Vernstand). Cfr. Jay, M., La Imaginación Dialéctica. Una bistoria de la escuela de Frankfurt, traducción de Juan Carlos Curutchet, Madrid, Taurus, 1989, p. 112. 
particular la de Jürgen Habermas y la de Albrecht Wellmer; por otro lado, la del comentarista español Juan José Sánchez. El aporte teórico de este artículo consiste en advertirle a este último autor que, en su justificado afán de distanciarse de la lectura habermasiana y de la postmoderna, termina debilitando el tono contradictorio y negativo de la filosofía conjunta de Adorno y Horkheimer.

Palabras clave: Ilustración, razón instrumental, crítica radical, aporía, contradicción performativa.

\section{Abstract}

This paper aims to offer an analysis of the critique of reason developed by Max Horkheimer and Theodor W. Adorno in three of his most important books: Dialectic of Enligbtenment, The critique of instrumental reason and Minima Moralia. Two fundamental questions are posed: Does the thought of the authors set a radical critique? If this is the case, wouldn't it imply a series of meta theorical problems and contradictions? In order to treat these questions, the statement is divided into two parts. The first explores the recurring issues of the critique of reason. In the second, we elaborate a brief reconstruction of two opposite hermeneutics of Horkheimer and Adorno's works: on the one hand, the lecture of Frankfurt School's second generation (Jürgen Habermas and Albrecht Wellmer); on the other hand, Juan José Sánchez's exposition. Our principal contribution to this debate is to warn Sánchez that, in his justified intention of separating from Habermas and postmodern's reading, he finally weakens the contradictory and negative tone of Adorno and Horkheimer's philosophy.

Key words. Enlightenment, instrumental reason, radical critique, aporia, performative contradiction. 